\title{
ADRITYLA, A NEW MILLIPED GENUS (CHORDEUMIDEA: CONOTYLIDAE)
}

\author{
By Nell B. Causey ${ }^{1}$ \\ Introduction
}

This is the second of a scries of papers on the widely dissimilar North American species formerly assigned to the genus Conotyla. In the first (Causey, I96I), the genus Austrotyla was proposed for coloradensis, humerosa, montivaga, and specus. The remaining species will be reviewed and the basal region of the gonopods described in subsequent papers.

A grant from the National Science Foundation (G-I 4486) made the completion of this paper possible.

I am grateful to Dr. Herbert W. Levi for the loan of the specimens of Conotyla deseretae in the Museum of Comparative Zoology.

\section{Genus Adrityla, new}

Type species. Conotyla deseretae Chamberlin, I9ı, by monotypy.

Diagnosis. Large bodied (length to $24 \mathrm{~mm}$.), pigmented conotylinids of 30 body segments, distinguished especially by the modification of legpair io $\left(8^{1}\right)$, of which the coxa is greatly enlarged and lobate and the telepodite is reduced to 2 or 3 minute segments. The sternum of the anterior gonopods is divided, and the small sternites are fused to the base of the gonopods. The latter are unsegmented and larger than the coxites of the posterior gonopods.

Relationships. The inclusion of this genus in the subfamily Conotylinae is justified by the following sexual characters of the male: the unsegmented anterior gonopods, the retention of a division between the coxal and prefemoral segments of the posterior gonopods, and the absence of coxal glands on legpair i i $\left(8^{2}\right)$. The divided sternum of the anterior gonopods suggests a close relationship with the AustrotylaTaiyutyla line rather than with Conotyla, which has this sternum undivided. The remarkable modification of legpair io surely occurred independently in Adrityla, as it has in other widely separated chordeumids.

Distribution. Utah.

$$
\begin{gathered}
\text { Adrityla deseretae (Chamberlin), new combination } \\
\text { Figures } \mathrm{I}-4
\end{gathered}
$$

Conotyla deseretae Chamberlin, 1910, Ann. Ent. Soc. Amer. 3 (4) :235-236, pl. 31, figs. 3-8; pl. 32, figs. 1-7. Loomis, 1943, Bull. Mus. Comp. Zool. Harvard $92(7): 381$. Chamberlin and Hoffman, 1958, U. S. Nat. Mus. Bull. 212:98.

\footnotetext{
${ }^{1}$ Fayetteville, Arkansas, and Gulf Coast Research Laboratory, Ocean Springs, Mississippi.
} 
Types. Present location of male holotype unknown. Two larvae, undoubtedly metatypes, from Mill Creek Canyon, Salt Lake Co., Utah, and my plesiotypes ( $\sigma^{\pi}$, ) from South Willow Canyon, Toocle Co., Utah, are in the Museum of Comparative Zoology.
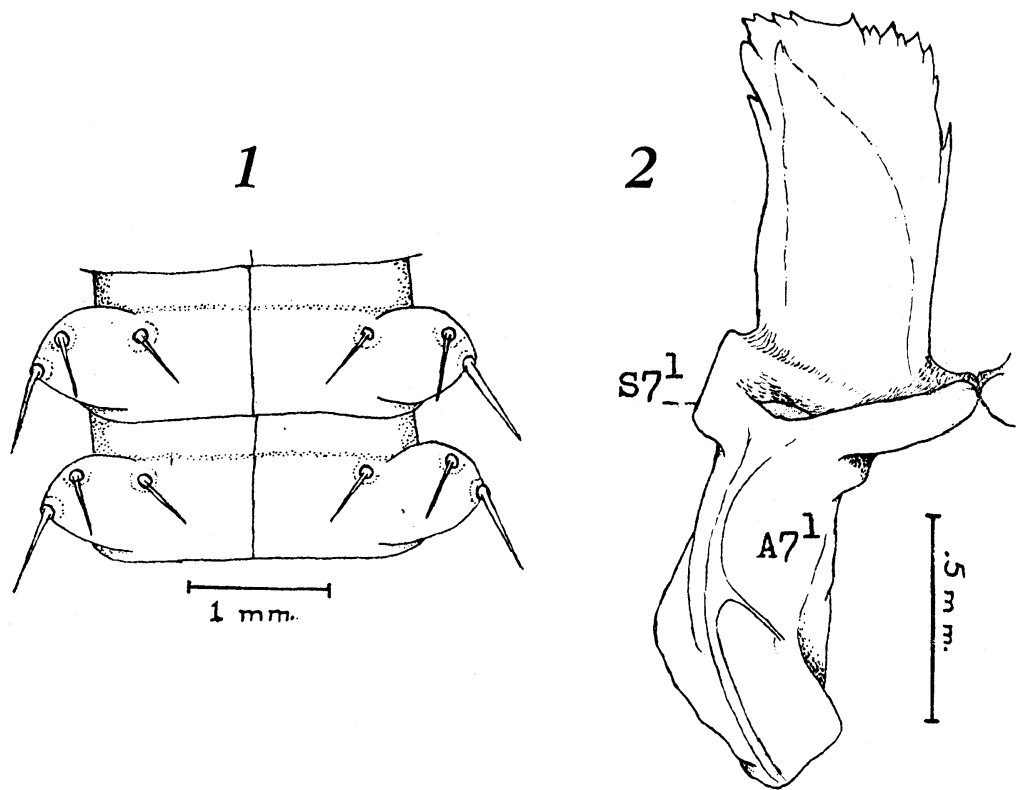

Figures 1, 2. Adrityla deseretae (Chamberlin). 1. Segments 10 and 11, dorsal view. 2. Left anterior gonopod, anterior view.

Type locality. The Wasatch Mountains, Salt Lake Co. and Utah Co., Utah.

Range. The Wasatch Mountains in central and northern Utah (Chamberlin and Hoffman, 1958).

Description. Length 22 to $24 \mathrm{~mm}$., width 2.6 to $3 \mathrm{~mm}$., the $0^{\pi}$ larger than the $q$. Body reaches its greatest width at segment 8 or 9 . Dorsum with a dark brown medial longitudinal band; pleura with a brown longitudinal band along the lower surface of the paranota; venter, legs, and remainder of dorsum light brown to yellowish; antennae dark brown. Ratio of length and width of collum approximately $1 / 2$. Paranota with the typical conotylinid shape and position are on segments 2 through 25 (Fig. I). Segmental setae acute; on typ:cal scgments the external setae are markedly longest, about 0.5 $\mathrm{mm}$., and the medial and internal (nearest the dorsomedial furrow) 
setae are about $0.35 \mathrm{~mm}$; the relative distances between them are as follow:

$$
\frac{\text { med. seta }- \text { ext. seta }}{\text { med. seta }- \text { int. seta }}=\frac{1}{3} \quad \frac{\text { dorsal furrow }- \text { int. seta }}{\text { int. seta }- \text { med. seta }}=\frac{1}{3 / 4}
$$

Mentum undivided. Clypeus, frons, and vertex with the usual short, unequal setae. Eyes triangular, from 23 to 25 black ocelli arranged compactly, but not touching, in rows of $1,7,6,5,4$ (3), 2 ( I), Antennae slender, the length approximately $4.3 \mathrm{~mm}$. in the $\sigma^{7}$ and 3.3 in the 9 .

In the male, legpairs $\mathrm{I}$ and 2 are about two-thirds the length and thickness of the following legs; legpairs 3 through 7 are shorter and thicker than the postgonopodal legs and segment 4 bears an inconspicuous rounded protuberance on the mesioproximal surface; the ventral surface of the coxa of legpair 7 is conspicuously swollen; the ventral surface of the tarsus of all legs from the third to about the middle of the body is pulvillar; legpair Io $\left(8^{1}\right)$ is highly modified by the enlargement of the coxa and. the coxal sac and by the reduction of the telopodite; and legpair I I $\left(8^{2}\right)$ has the coxa slightly swollen but lacks a coxal sac or coxal perforation; the ectoventral surface of segment 2 of legpair i I bears a small, rounded, caudally directed lobe.

The anterior gonopod (Fig. 2) is an unsegmented, rectangular piece irregularly serrated on the ventral margin and directed down and slightly forward. In the coxosternal region it is contiguous with its homologue along a movable suture. The spiracle opens into a large depression near the anterior margin of the coxosternum.

The posterior gonopod (Figs. 3 and 4) consists of the usual three segments: I) a coxa with two elongated coxites, the mesial one inconspicuous and narrowly attenuated, and the more lateral one longer, stouter, clavate, warty on the apical surface, and covered distad by the larger coxite of legpair Io; 2) a slender prefemur (one-third the length of the femur) with a setose lobe on the mesiodistal surface; and 3) a large oval femur (the ratio of the length to the thickness is $I / 3$ ) with an irregular pigmented pit on the caudal surface near the apex. The sternum is thin in the midline and bent sharply ventrad; laterad it is fused with the coxae and thickened; the spiracles open from large pigmented pits near the ectocephalic angles.

Leg Io consists of two regions: I) an enlarged coxosternum with one massive coxite that curves back over leg i I and covers the apical region of the larger of the two coxites of the posterior gonopod, and 2) a minute telopodite of 2 or 3 unequal segments that cannot be 
I 34

Psyche

[I)cember
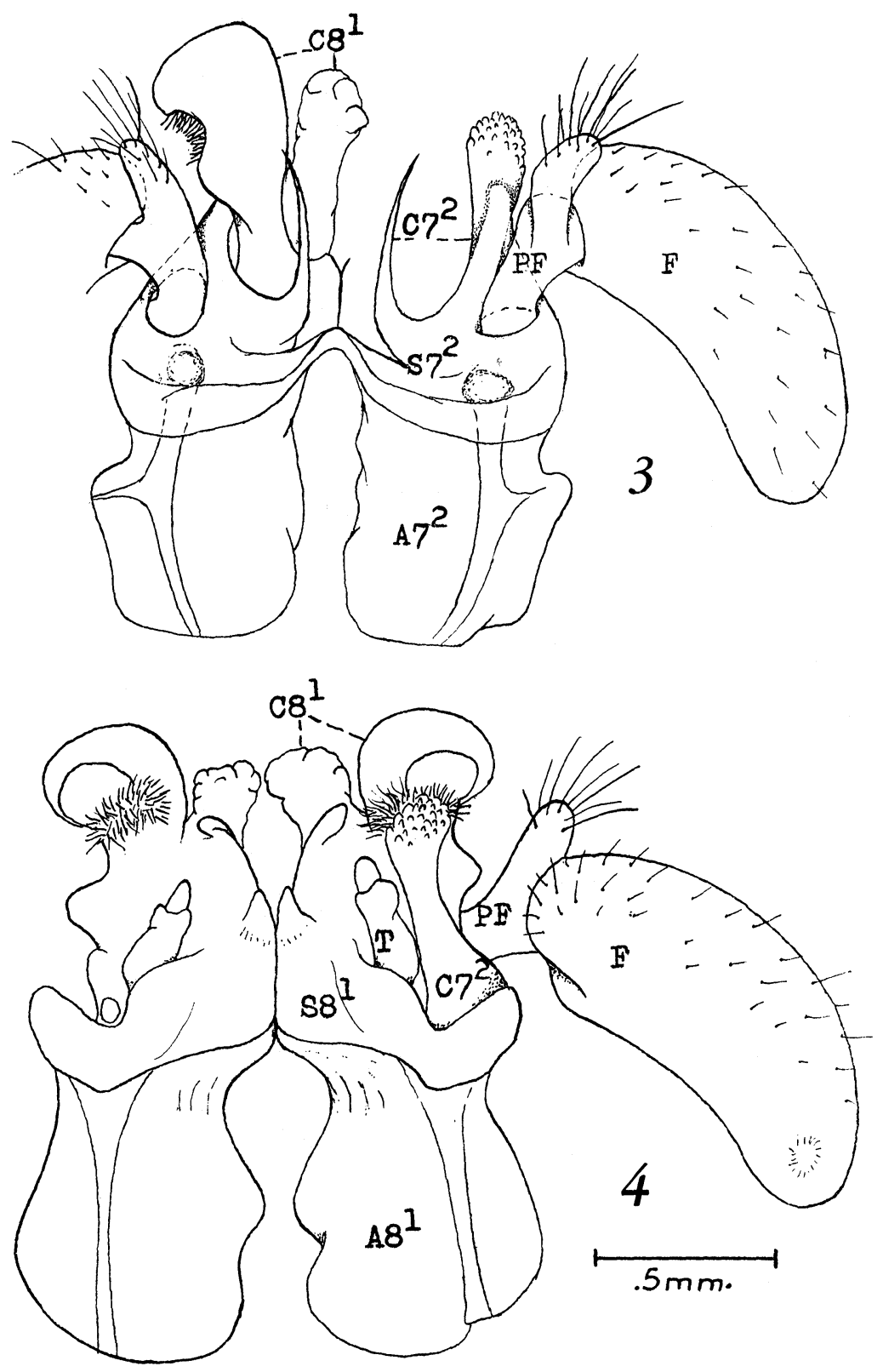
seen unless leg II is removed. The coxite is elongated, broadened and rounded distad, smooth on the anterior surface, and thickly setose over part of the more complex posterior surface; a subapical flange is on the ectal surface, and near the base of the mesial surface is a large perforation through which the enlarged, soft coxal sac projects. The coxal sac is contiguous with its homologue in the midline. The sternum is divided and coalesced with the coxa, forming a thick, short coxosternum which is contiguous with its homologue along a movable suture; the inconspicuous spiracles open on the ectal surface of the coxosternum.

Appendages $7^{2}$ and $8^{1}$ (the posterior gonopods and legpair Io, respectively) fit close together, but there is no fusion, and with careful dissection they can be completely separated.

In the female, the setae on the vulvae are unusually long. The legs are typical of the family.

Emendations. In the original description, Chamberlin (I9IO, p. 236) incorrectly interpreted the coxites of legpair Io $\left(8^{1}\right)$ as part of the anterior $\left(7^{1}\right)$ and posterior $\left(7^{2}\right)$ gonopods. The correct legends of plate 31, figures 4-7 are: figure 4, legpair IO, caudal aspect; figure 5, anterior gonopods and parts of posterior gonopods and legpair IO, cephalic aspect; figure 6, left gonopods and tenth leg, lateral aspect; posterior gonopods, cephalic aspects. Only legpairs 4 and 5 were represented (Pl. 32, Figs. 2-6) as having a small lobe on the mesioproximal surface of segment 4. I have found that legpairs 3 through 7 have segment 4 similarly modified; possibly there is some variation of this character. A large promentum was indicated in plate 32, figure 7 . There is no promentum; the small triangular space anterior to the mentum is covered only by a membrane.

Variations. The ventral margin of the anterior gonopods is irregularly serrated in each of the 4 male specimens that I have examined. The serrations vary between 3 and 14 or 15 . A possible variation in the lobation of the pregonopodal legs was mentioned in the preceding paragraph.

Material Examined. UTAH : Mill Creek Canyon, Salt Lake Co., larvae (MCZ) [? metatypes]; South Willow Canyon, Tooele Co.,

Figures 3, 4. Adrityla deseretae (Chamberlin). 3. Posterior gonopods and left tenth leg, anterior view. 4. Left posterior gonopod and legpair 10, posterior view. (Abbreviations: $\mathrm{A} 7^{1}, A 7^{2}, \mathrm{~A} 8^{1}$, sternal apodemes of anterior gonopod, posterior gonopod, and leg 10 , respectively; $\mathrm{C}^{2}, \mathrm{C} 8^{1}$, coxites of posterior gonopod and leg 10, respectively; F, PF, femur and prefemur of posterior gonopod, respectively; $\mathrm{S}^{1}, \mathrm{~S}^{2}, \mathrm{~S} 8^{1}$, coxosternites of anterior gonopod, posterior gonopod, and leg 10, respectively; $T$, telopodite of leg 10.) 
July 5, I953, I $0^{\star}$, I \&, W. D. Hester (MCZ); American Fork Canyon, Timpanogos Park, Utah Co., June I 4, I952, W. D. Hester, $3 \sigma^{\pi}, 8$ \%, larvae (NBC).

Causey, Nell B.

\section{Literature Cited}

1961. Austrotyla, a new milliped genus (Chordeumidea: Conotylidae: Conotylinae). Proc. Biol. Soc. Wash. 74: 251-266, Figs. 1-10.

Chamberlin, Ralph V.

1910. Diplopoda from the western states. Ann. Ent. Soc. Amer. 3(4): 233-262, pls. 30-43.

Chamberlin, R. V. and R. L. Hoffman.

1958. Checklist of the millipeds of North America. U. S. Nat. Mus. Bull. 212 , p. 212. 

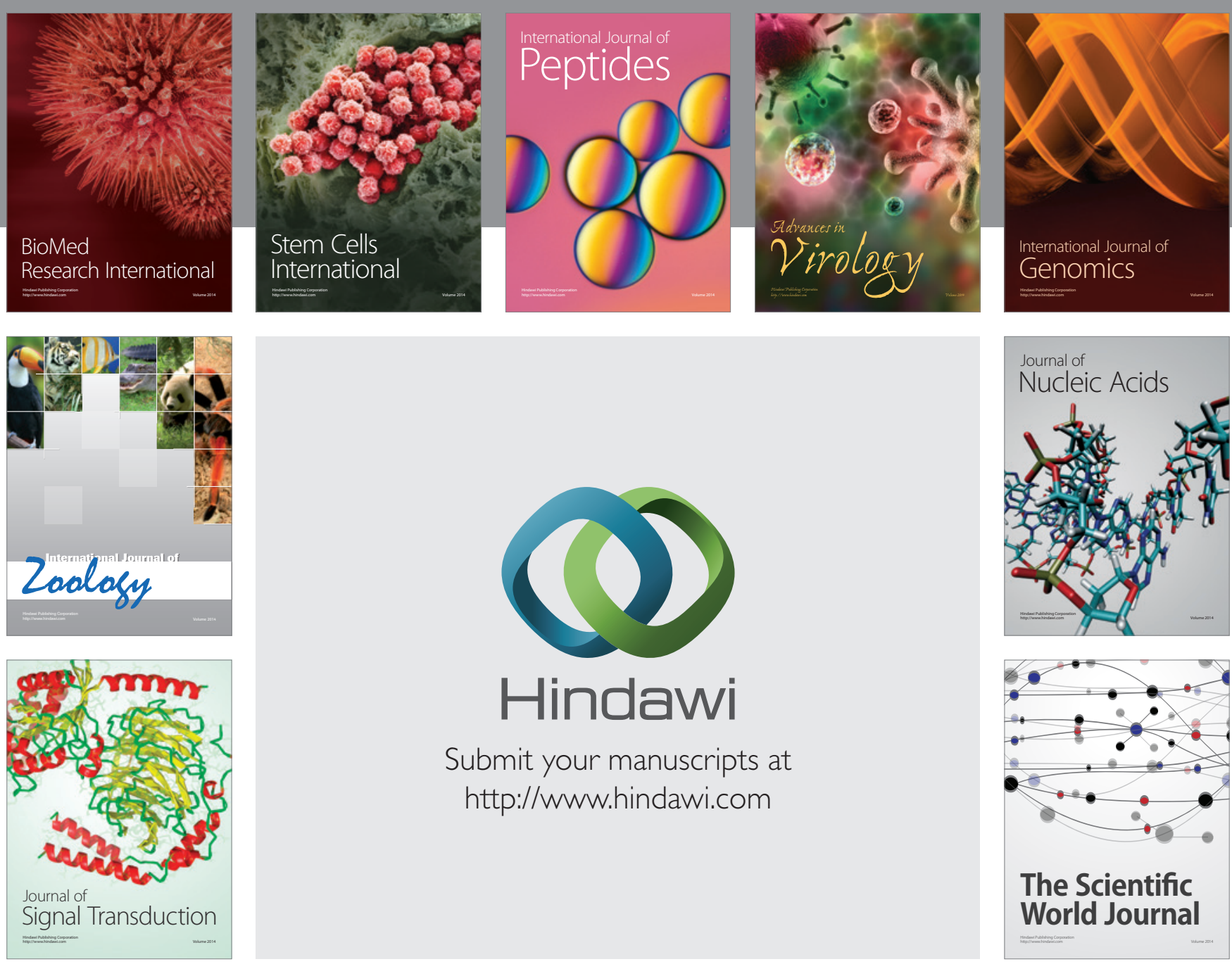

Submit your manuscripts at

http://www.hindawi.com
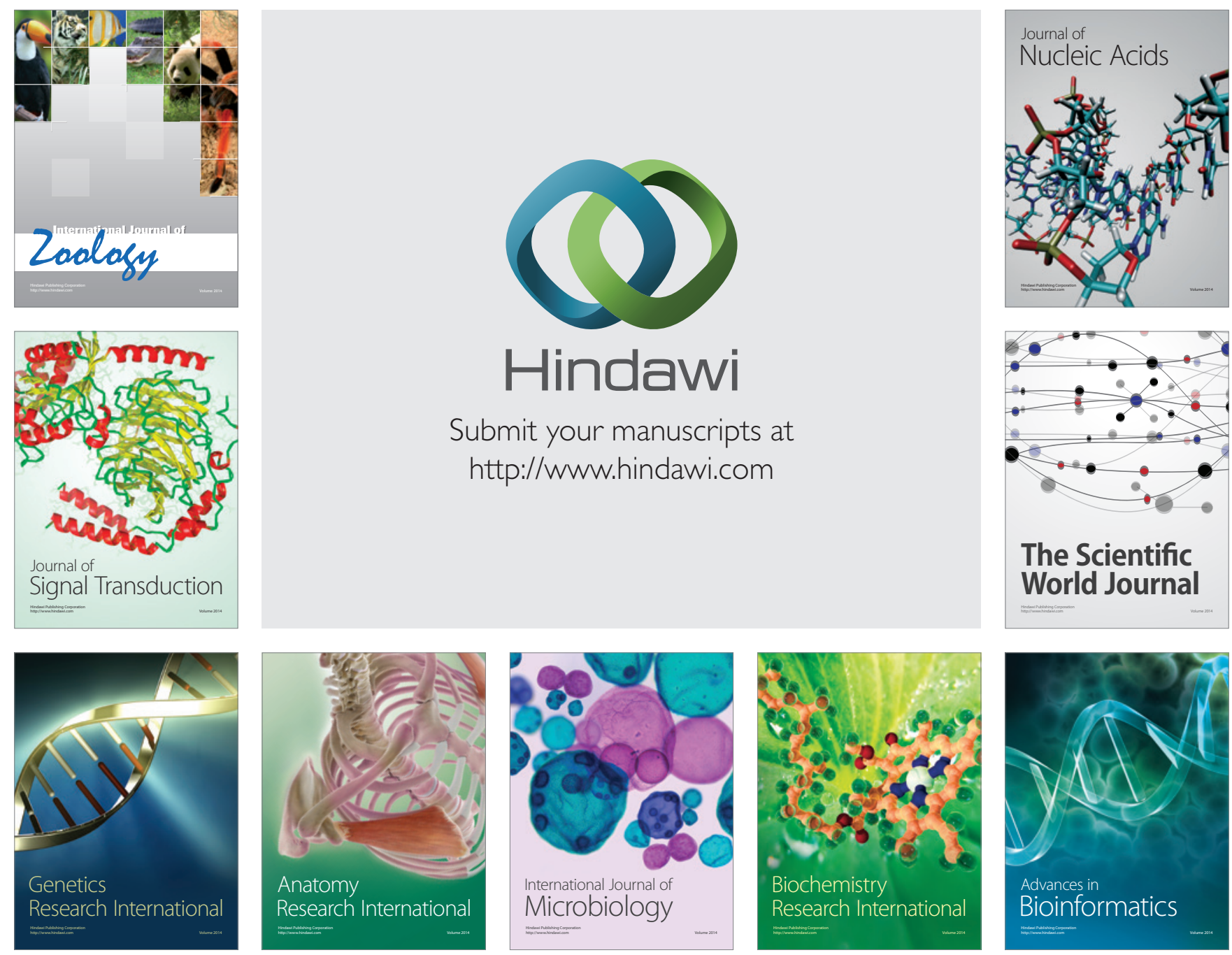

The Scientific World Journal
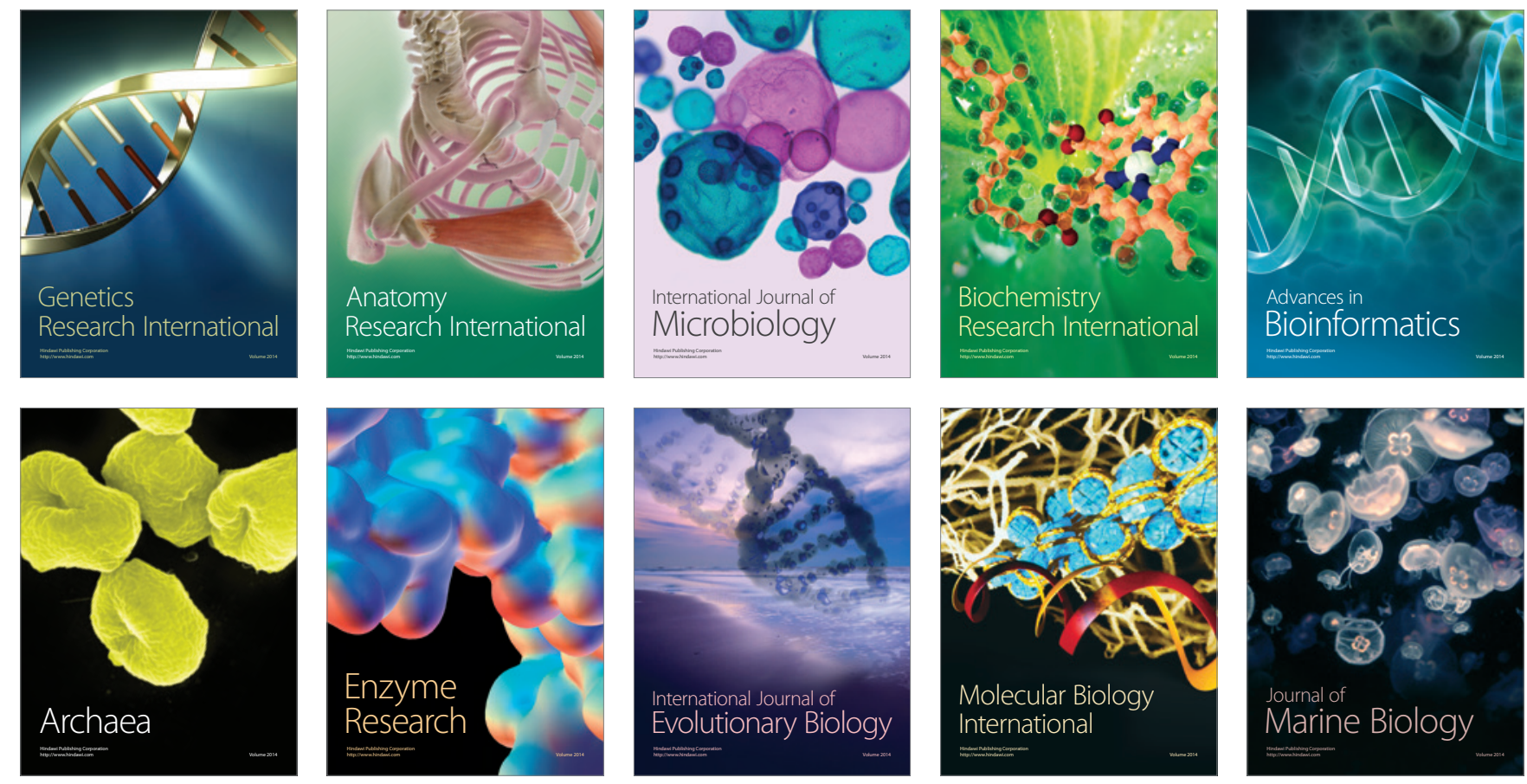